That symbolic violence is delivered, through literary elements; especially character and point of view. The story used character's speeches and point of view to deliver the symbolic violence. Therefore, it emphasizes Bourdieu's concept that, symbolic violence is effectively delivered through language or discourse. Related to the impact of the symbolic violence reflected in the story, the community absorbs the symbolic violence through their obedience. They accept all of the rules as the best way of life, without asking the reasons of their obedience. On the other hand, the symbolic violence also creates resistance, as reflected in the character of Jonas, when he breaks the rules of the community, in order to change the ways of life in the community.

KEYWORDS: Symbolic Violence, the Community and Creates Resistance

Received: Aug 16, 2017; Accepted: Sep 07, 2017; Published: Sep16, 2017; Paper Id: IJELOCT20176

\title{
INTRODUCTION
}

\section{Background of the Study}

Most people think that, violence can only be done physically or verbally. Physical violence is provided physically and it gives impact to the victim's physical destruction. Meanwhile, verbal violence is delivered through words or language, and it is able to destroy the victim's psychology as traumatic feeling. Because of that impact, both physical and verbal violence victims usually recognize that, they are getting violent.

\footnotetext{
${ }^{1}$ The author is an awardee of Lembaga Pengelola Dana Pendidikan (LPDP) scholarship. This research is supported by LPDP.
} 
Besides, both the violence, there is a kind of violence in which the practice is very smooth, so the victims do not recognize that, they are experiencing violence. The destiny of this violence is dominating and the actors who do the domination usually have power. Through their language or discourse, they intend to dominate others. Although, this violence does not give physical impact, it maintains several kinds of destruction, including destruction of life, opportunity, personal liberties of freedom, personal choice of action, personal choice of conscience, etc. Pierre Bourdieu called this violence as symbolic violence. "Symbolic violence is violence wielded, with the tacit complicity between its victims and its agents, in so far as both remain unconscious of submitting to or wielding it" (Bourdieu, 1997: 141).

This research analyzes the symbolic violence in a children's book entitled The Giver. The Giver is a children's story, written by Lois Lowry in 1993 and it was published in New York. This novel wins several awards; one of them is the Newbery Medal in 1994. The story is about an eleven year old boy, who lives in a perfect world where the people never feel pain, war, fear, and any bitterness feeling. People in this community cannot also enjoy pleasure, such as to see color, to hear music, and to feel love. Life in the community is so predictable, orderly, and painless. In addition, people in the community live in under control, and they have no freedom to choose their own choices. Unfortunately, they passively accept all the rules and customs, and never ask why the customs have to be obeyed.

Based on the reasons, the practices of symbolic violence are reflected in the novel. It can be seen through, how the citizens accept the rules of the community and never ask why the rules must be obeyed. Whereas, the rules take their rights as human, such as rights of freedom and live. Because of the reasons, this research analyzes the symbolic violence reflected in The Giver. The focus of the research area; to find what kinds of symbolic violence happens in the story; how that symbolic violence is delivered, and what are the impacts of the symbolic violence reflected in the story.

The discussion of symbolic violence is interested because, it is relevant to our life today. Nowadays, people often experience symbolic violence, but they do not recognize about what they experience. Whereas, there is a serious impact if this violence happens continuously. Therefore, the author hopes that this research will be useful for people, to understand and be more critical in recognizing symbolic violence, which potentially happens anywhere and anytime.

\section{Research Methods}

This research used qualitative research approach, because the goal of this research is to interpret a literary text. The data of this research are non-numeric and the phenomena studied are described in the form of words. This is in line with Vanderstoep and Johnston (2009: 7), that in a qualitative research, a researcher will have to produce a narrative or textual description of the phenomena under studied.

The primary source of this research is a children's book entitled The Giver, written by Lois Lowry in 1993 and was published in New York. The novel consists of 23 chapters and 179 pages. The research data are the data, which indicate symbolic violence and the ways the symbolic violence are represented in the novel. This data can be in the form of words, phrases, clauses, or sentences.

Lincoln and Guba (in Vanderstoep and Johnston, 2009: 188) argue that, the best instrument for a qualitative research is human. Therefore, the key instrument for collecting the data in this research is the researcher herself. As the main instrument, the researcher took a role as the designer, data collector, data interpretation, and she also reported the finding of the study. 
In the process of collecting the data, the researcher employed several steps. First, the researcher read and reread The Giver comprehensively to get a deeper understanding, to the content of the text. Second, the researcher collected the data by underlining and taking simple note, in the form of words, phrase, clause, sentences, and paragraphs related to the research objectives. Third, the researcher organized the data, by giving code to each datum of the first research objective. Then, the researcher carefully reads the data, in order to have a clear interpretation. Finally, the data were categorized into thematic meaning, related to the objective of the research.

In order to avoid subjectivity in the analysis and interpretation, it is important to validate the result. To ensure the quality of the findings, the researcher applied trustworthiness. According to Moleong (2010: 173), there are four types to check trustworthiness: credibility, transferability, dependability, and conformability. Credibility is concerned with the accuracy of the data and it is obtained by conducting triangulation. Basically, there are five types of triangulations: by sources, by method, by researcher, by theories, and by checking member. Related to the discussion of conformability, the aim is to measure, how far the finding and the interpretation of the data are truly based on the data. To get the degree of conformability, the researcher provided all data and asked the peer reviewers, to give suggestions and opinion about the analysis. Peer reviewers in this research were students of Literary Study, Universitas Indonesia. They were LalaIsnaHasni and Sri WarsidahRahmi. The peer reviewers have understood theories of symbolic violence and children's literature, and the story of The Giver.

\section{FINDINGS AND DISCUSSIONS}

This part consists of three parts. The first part is analyzing the kinds of symbolic violence, represented in the novel. The second part is analyzing the ways the violence is represented, and the last part is analyzing the impacts of the symbolic violence reflected in the story.

\section{Kinds of Symbolic Violence in the Giver}

The researcher finds that, there are five kinds of symbolic violence happen in the story. They are symbolic violence to repress choices, to eliminate individuality, to manipulate history, to hide feelings, and to end one's life

\section{Symbolic Violence to Repress Choices}

According to Bourdieu (1992), the victims of the symbolic violence do not recognize that, they experience violence. They absorb the violence without noticing that, there is something wrong with what they do. In addition, symbolic violence can happen everywhere and it is difficult to be avoided. "Symbolic domination... is something you absorb like air, something you don't feel pressured by; it is everywhere and nowhere, and to escape from that is very difficult" (Bourdieu, in Bourdieu \& Eagleton 1992e: 115). Thus, the victim of symbolic violence happens in a very smooth way, so the victims do not feel it as a compulsion or destruction.

This phenomenon happens to The Giver, where the community in the story does not recognize that, they experience the symbolic violence, especially the violence of repress their freedom to choose their own choices. Life in the community is so predictable, orderly, and painless. People in the community live in under control and they have no freedom to choose their own choices. Unfortunately, they passively accept all the rules and customs and never ask why the customs have to be obeyed. The reasons of the Committee are that, they want the community safe. The Committee is scared, if the community will choose the wrong choice. Jonas' society chooses permanently safety rather than liberty. 
Unfortunately, the citizen never asks about their way of life. They accept the rule as it is.

A mistake. She made a mistake. But Jonas knew, even as he had the thought, that she hadn't. The Chief Elder made no mistakes. Not at the Ceremony of Twelve. (The Giver, 57).

The text above happens when Ceremony of Twelve happens, and The Chief of Elder skips Jonas' assignment. Through Jonas' point of view, it shows how powerful The Chief Elder is, as the leader of the community is. The thought that, The Chief Elder never makes mistakes proves that, people believe the Chief of Elder always right in their own policy and that is why her decision is reasonable to obey.

Another example which proves the practice of symbolic violence is shown in the dialogue below:

"But the Receiver-in-training cannot be observed, cannot be modified. That is stated quite clearly in the rules. He is to be alone, apart, while he is prepared by the current Receiver for the job which is the most honored in our community." (The Giver, 61)

The phenomenon is kind of symbolic violence, which is done through discourse. The dominant people, or the Committee, are the holder of that wisdom. Through their language and discourse, they succeed to deliver the idea that, their policy is the best choice for the society. They cultivate to the people that, life in Sameness is the suitable choice, rather than in diversity. The Committee tells the community that, diversity is dangerous and threatens the stability of the community.

The capability of cultivating the idea proves that, the idea is delivered in a smooth way, so the citizen does not realize that, actually there is something taken from them, that is their right to life liberty. The community lost their idea that, as human they have right to choose their choice freely.

Therefore, it proves Bourdieu's statement that; symbolic violence usually is done in a very smooth way, so the victims do not realize that they are experiencing violence. In this case, the victim is the society, and the actor who does the symbolic violence is the holder of the system in the community or the Committee.

\section{Symbolic Violence to Eliminate Individuality}

In the community, people are designed to live in Sameness. The community eliminates personal variation. This condition drives the citizen to loss their differences. They have to live in routine as structured by the rules. Nothing is different in the community. On the contrary, if there is a person who is different from the society, she or he will be categorized as abnormal. Then, the abnormal person can be considered as dangerous and she or he will be thrown from the community.

Life in sameness has chosen by the community for a long time. Life in the community is painless, warless, colorless, and mostly emotionless. It is predictable and everything is under control. For example, everyone is assured a job, a spouse, and two children who were born by the Birthmothers. There is no freedom to choose a particular job, spouse, family arrangement, and emotions or ideas. These problems happen because; the community has eliminated all the memories of pain and pleasure, and locked those memories in The Giver's mind. In addition, the community controls the characteristic of the people's physique. For example, almost of the community have darker eyes. The Committee even controls the weight of the people's body since they were born. 
"Our people made that choice, the choice to go to Sameness. Before my time, before the previous time, back and back and back. We relinquished color when we relinquished sunshine and did away with differences." He thought for a moment. "We gained control of many things. But we had to let go of others."

(The Giver, 95)

There is a serious impact of this kind of sameness life. Since they have never experienced the real suffering, they cannot appreciate the real joy of life. Because, they cannot experience the real happiness, they cannot understand the meaning of sadness. This kind of life creates monotony, and it will make people, lack of appreciating others uniqueness.

According to Bourdieu (1992), domination is the root of violence. The goal of domination itself is to get the eternal power. Meanwhile, the condition of sameness is the impact of domination; it is the product of the Committee's control of the society. Thus, it can be read that the purpose of the Committee to control the society's life in the monotony life is to drive their power. Despite, they deliver their power in a very smooth way.

\section{Symbolic Violence to Manipulate History}

Another kind of symbolic violence happens in this story is, symbolic violence of manipulating memory. Memory is the ability of the mind to store and recall past thoughts, experience, knowledge, etc. Having memory means having history, and it is true that history is a priceless legacy which is able to teach people the best way of life for their future.

Unfortunately, memory is hidden in this community. Thus, it can be said that they hide the history of their life. It can be seen through the chapter, in which The Committee of the community hides the memory of bitterness. They did not let the community to see the true life in the past. On the contrary, they hide the true bitterness and joyful memories in The Giver's mind. Whereas, history is symbolic violence of manipulating memory or history happens several times in this story. For example, the Chief of Elder refuses to talk about the failure of the Receiver before Jonas, because she does not want to recall the memory of discomfort.

When the Receiver fails to take his or her assignment, the memory will release or loose. The looser of the memory will make the community loss of the memory, so they cannot use it when they need it to be a suggestion. For example, when the community faces something that, they have not experienced before, they will call The Giver to use the memory and give them advice. Finally, it will create chaos in the community.

Hiding the memory is not only done by the Committee, but also Jonas' parents. They want to manipulate the memory about the girl who becomes The Receiver. Instead of explaining the truth to Jonas, the parents say that the girl's name is forbidden to speak. The parents close the conversation about the girl, by saying that Jonas has gotten the best honored. It indicates that, the parents avoid the conversation about the Receiver.

Another example that proves the symbolic violence of hiding history can be seen, how the Committee save the books from the people. Actually, there are so many books in the community and it is placed in Annex room. It is a room where The Giver lives and transferring memories to Jonas. Thus, only The Giver and The Receiver can access the books. As we know, the book is symbolic of knowledge. We will know many things, just by reading books. When the access to read is closed, it means that, we have no access to get knowledge, including history. Keeping books from people's hand means keeping knowledge from people's eyes. It symbolizes that, people cannot also know the history of the community. The memory or history of the community only can be grabbed by The Giver and The Receiver, two people who will hold 
the memory of the society.

But this room's walls were completely covered by a bookcase, filled, which reached to the ceiling. There must have been hundreds - perhaps thousands-of books, their titles embossed in shiny letters.

Jonas stared at them. He couldn't imagine what the thousands of pages contained. Could there be rules beyond the rules that governed the community? Could there be more descriptions of offices and factories and committees?

From the text above, we can see how Jonas impresses about the books. He does not know that, actually there are many books that exist in the world. For a long time, he just knows the books in his dwelling. He had never known that other books exited. It symbolizes that, the Committee hides the books from the people. Furthermore, it symbolizes that the Committee keeps away the knowledge, including the knowledge of the history of the community itself.

\section{Symbolic Violence to Hide Feelings}

Emotion or feeling is part of the human being. Emotion makes people to be able to know different feeling. It can be sad, happy, anxiety, love, hate, etc. It is important to have felt because, it is a tool to express and experience life in balance.

Emotion and feeling are not part of the important thing in the community. The community intentionally eliminates feeling of the citizen. Therefore, they do not know how to feel sad, happy, love, or hate. They do not know the concepts of those kinds of feeling. The symbolic violence of expressing feeling is shown in the dialogue below:

"And what about Fiona? She loves the Old! She's in training to care for them. Does she know yet? What will she do when she finds out? How will she feel? Jonas brushed the wetness from his face with the back of one hand.

"Fiona is already being trained in the fine art of release," The Giver told him. "She's very efficient in her work, your red-haired friend. Feelings are not part of the life she's learned." (The Giver, 153)

The dialogue above happens, when Jonas feels angry with his father and to the community, after seeing the video of the release. Seeing the video made him understand what the true meaning of release is. When someone is released, it means that he or she is killed. After knowing its meaning, Jonas remembers his friend who has assignment to care old people in The House of The Old. Jonas thinks about Fiona, because he believes that Fiona does not know yet about the meaning of release. He thinks that, Fiona must be very sad when she knows that, the old people who will be released means that, he or she will be killed. Responding Jonas' statement, The Giver explains that, Fiona is trained in a very good way to release old people; therefore, she will not feel sad as Jonas feels. In addition, The Giver states that feelings are not the part of Fiona's life.

The phenomenon reflects that, in the community, feelings are not part of their life. They do not need feeling to any activities in their daily life. That is why, life in the community is so painless. They do not know how to feel sad, angry, happy, even love, although they live together in a structure of "family".

Another symbolic violence of expressing feeling is also shown in the part, after Jonas receives the memory of love and family. After receiving the memory, Jonas tries to ask about the concept of love to his parents. He wants to know whether his parents love him. Instead of getting answers, about how his parents love him, the parent state that, using the 
word love is forbidden in the community. Love is undetected concept, and that is why they cannot use that word. Therefore, the father asks Jonas to use the precise language and not to say the general world. For them, love is too general to use.

Through, in those parts, it can be seen how The Committee controls the society's feeling. It can be read as Committee's efforts, deliver their power in managing the people's life. By excusing for the sake of safety, the Committee even causes feeling as an unimportant part of people life and the people do not obey the control happily. Thus, it proves the domination of the Committee to the community.

\section{Symbolic Violence to Finish One's Life}

Life is human's fundamental right. Every human has a right to live and to live their life as good as possible. Thus, it is forbidden for people to take one's life. Killing is one of despicable act, because it takes human's right to live.

Symbolic violence of finishing one's life happens in this story, in the form of release. It becomes the practice of symbolic violence, because the actor kills the people who will be released. The Committee, however, assigns the member of the community, in order of doing the release. The assigner will be trained in a very good way, to release old people; therefore, she or he will not feel sad when releasing people.

In addition, the Committee tells to the people that, release is one of the parts of life. People who will be released even do not refuse and accept the rules as part of their life. Whereas, they do not know where they go or what will happen after they are released. On the contrary, the person who is released is happy and cheerful when they face the ceremony of release, as the citizens who attend the ceremony. They are happy and celebrate the ceremony as a happiness party.

Jonas slowed the strokes of his hand on her back thoughtfully. "Larissa," he asked, "what happens when they make the actual release? Where exactly did Roberto go?"

She lifted her bare wet shoulders in a small shrug. "I don't know. I don't think anybody does, except the committee. He just bowed to all of us and then walked, like they all do, through the special door in the Releasing Room. But you have seen his look. Pure happiness, I'd call it."

(The Giver, 32)

The dialogue above was said by Larissa to Jonas. Larissa is an old woman, who lives in the House of Old and being taken care of Jonas. Jonas asks to Larissa, what release is. From the Larissa's explanation, it can be seen that, actually the people of the community do not know what is release, what happens to them after being released, and where will they go after being released. Instead of feeling sad, although they know that, they will never come back to the community again, the people who will be released look so happy. They even make a lovely goodbye speech. In addition, the people attend the ceremony, to celebrate the ceremony in a happy way. They have toast, raise their glasses, and cheer. It symbolizes happiness. They do not know the meaning of release is, except the committee.

Those phenomena, once again, also show how symbolic violence works in this society. The citizens do not know the meaning of release, but never asks what release means to the committee is. They obey the policy as it is, without need to know what the rule it is. Whereas, the rule is so essential because, the impact even take their freedom to live; because release means killing. People who are released never come back to the community, because it is killed by the committee. 
However, the Committee tells that those people are sent to Elsewhere and the community believes about it.

\section{The Ways the Symbolic Violence are Delivered}

The Giver is a children's literature. According to Lukens (Lukens, 1999: 79-217), basically, there are no differences of literary element construction between children's literature and adult's literature. Both of them consist of literary elements, such as character, plot, theme, setting, point of view, style, and tone. Authors of children's literature use literary elements to deliver opinion, knowledge, experiences, etc. In addition, literary elements are also used to transmit the symbolic violence in this story. Therefore, in order to know the way the author delivers the symbolic violence in a story, it is important to observe the literary elements of the story.

The researcher finds that, the symbolic violence is delivered through two prominent literary elements; they are character and point of view. Although, the story uses both characters' actions and conversation to reveal the symbolic violence, the characters' conversations are most frequently occurring to deliver those symbolic violence, rather than through the actions.

According to Bourdieu (see Bourdieu in Bourdieu and Eagleton, 1992e: 111), language can be the powerful media to transmit domination. Bourdieu sees language, not only a medium of communication, but "an instrument of power and action". Language itself is a form of domination. The dominant people will deliver their power, through language to the dominated people. In order to deliver their domination, they will choose word, as good, as possible, so that the dominated people will absorb and obey what they say. The ability of playing words will decide the success of dominating others. The dominant people will select the accent, intonation, even dictions in the process of delivering power.

The dominant way people deliver their power through language is clearly shown in The Giver. The Committee, especially Chief of Elder always plays their words or sentences, to influence community's perspective. For example, in the part the Chief of Elder announces Jonas' assignment at the Ceremony of Twelve. She tells that, Jonas is assigned to be The Receiver, which is said as the most honored job in the community. The way she chooses the word "honor", actually has a purpose. She calls it as the most honored job, rather than the hardest job. Whereas, being The Receiver is hard. It needs a diligent effort. Jonas even has to scarify his childhood, when he is assigned to be The Receiver. Being The Receiver means, he becomes the protective agent to save the community's life. Thus, is it totally true that being The Receiver is an honored job?

It can be read that, the Chief of Elder wants to hide the sense of hardship in the front of the community. They play the words to play with people's mind. The purpose, of course, is domination itself. They want pursuance, so they choose the "sweet" word to get people's agreement.

"But the Receiver-in-training cannot be observed, cannot be modified. That is stated quite clearly in the rules. He is to be alone, apart, while he is prepared by the current Receiver for the job which is the most honored in our community." (The Giver, 61)

The concept of release also reflects how the Committee plays language to deliver the domination. Release means killing. People who will be released, means that he or she will be killed. However, people do not feel scared that, they will be released because; they do not know the meaning of release is. The Committee gives "a good understanding" that when people are released, they will go to Elsewhere. In addition, the Committee tells that release is one of the best ways to save 
the community's safety.

The Committee shows their success, doing their domination through language. Reason for using the community's safety, they create some rules. How the citizens obey the rules prove their success of domination, so they create the symbolic violence. Thus, it proves that, language has the powerful media to transmit domination, and it is delivered through the dialogs or conversations of the characters, in the story.

In addition, the author also uses point of view to deliver the symbolic violence happens in the story. Lukens (1999: 175) explains, "point of view is determined, when the writer chooses who is to be the narrator and decides how much the narrator is to know." Point of view is important in a story because, the credibility of a story depends on how much point of view successfully maintained. In addition, point of view becomes one of the most important tools, for an author to find the right voice for her or his novel.

The Giver uses limited omniscient point of view. According to Lukens, this kind of point of view has several characteristic, they are told the story from a third person's perspective, the author chooses the eyes of a certain characterusually the protagonist - to tell the story, and the author shows not only what the character sees and hears, but also what the character feels and believes. The Giver has limited omniscient point of view and it placed Jonas' perspective, as the medium to transmit the story. Through Jonas' perspective, the author shows the symbolic violence happens in the story. It is Jonas, who sees, hears, and feels the symbolic violence happening in the story.

Bellow, is the dialogue which shows symbolic violence, which is delivered through Jonas' point of view:

Almost every citizen in the community had dark eyes. His parents did, and Lily did, and so did all of his group members and friends. But there were a few exceptions: Jonas himself, and a female Five whom he had noticed had the different, lighter eyes. No one mentioned such things; it was not a rule, but was considered rude to call attention to things that were unsettling or different about individuals. Lily, he decided, would have to learn that soon, or she would be called in for chastisement because of her incentive chatter.

(The Giver, 20)

The dialogue happens when Jonas recognizes that, all of the community has the same characteristic, including in physics and emotions. The Committee designs the community to have the same characteristic, through applying some rules. Then, Jonas becomes the agent who can see and feel the designs. The reader can see the symbolic violence or domination of the community, through Jonas' point of view, such as the way he thinks and feels. Thus, it can be concluded that, Jonas' point of view is useful to understand the domination happens in this story. It is a Jonas' mind, that shows the readers, what and how the domination operates in the community.

\section{The Impact of Symbolic Violence Reflected in the Giver}

Bourdieu states that, the impact of symbolic violence is obedience. Obedience becomes the parameter of success, of the dominant people in transmitting their power. When the dominated people obey the rules or discourse, they apply to them, at the same time the dominant people would win. They accept the domination happily, almost without asking why they have to obey the rules the dominant people have. This kind of impact is clearly reflected in The Giver. The society absorbs and obeys the rules in the community, as the best way of life. They even enjoy with the way they live and accept all the rules happily. 
Furthermore, Bourdieu argues that, at a certain time, symbolic violence also potential to create resistance. The resistance even can be "harder" than the symbolic violence that they accept, because the form of resistance can be in the form of physical rebellion. Bourdieu (in Schubert, 2008: 196) calls this resistance as heterodox. According to Bourdieu, heterodox is potential happens because, actual rules of the society are socially and historically construction, so there is a chance to change the condition. Through heterodox discourse, the resistance is possible to do.

The resistance to the symbolic violence in The Giver is reflected by Jonas' action, after knowing the truth about the society. Jonas is shocked to know all the truth of life in the community, and he even feels sad and angry with the rules. He thinks that, memories should not only be saved by The Giver or The Receiver, but memories must be held by all the people who live in the community. Jonas' anger, then, inspires The Giver to make a plan change the rules in the community, forever. Meanwhile, they know that the only one way to change the rules of community is, by returning the memories of the past back to the community. Thus, the people will live with the memories again. Therefore, Jonas decides to escape from the community towards Elsewhere.

Jonas is brave to take the effect of his escape. He knows that, if he decides to escape, he has no opportunity to return to the community. In addition, if the community finds his escapade, he will be killed because the Receiver of Memory is not permitted to escape. He escapes when December Ceremony and takes Gabriel, a baby that will be released, with him. On their journey of escape, Jonas faces some difficulties. Those conditions make Jonas think, whether his decision to flee is the best choice or not. However, he continues to think, if he stays in the community his life will be unworthy. He will not be able to feel love, to see color, and to hear music. Moreover, there is no life for Gabriel too.

He uses the memories he has to face the difficulties. The feeling of hungry, exhausted, and cold makes them weaker and hard to walk. To warm themselves up, Jonas tries to call back some of memories of warmth that, The Giver has given to him. Unfortunately, they are too weak because, the all the memories almost leave him and have returned to the community. He is sure that, there are some people who are waiting for them there.

Therefore, Jonas' action to escape reflects his resistance to the rules of the community. He chooses to flee, although he knows that, there is a serious impact if the community finds him, because he will be killed. He chooses to struggle; in order to reach his destiny, he goes elsewhere. In this story, Jonas becomes the symbol of resistance. He is different from people in the community, who accept all the rules and domination. Jonas takes some efforts to fight the rules, in order to change the way of life in the community. Until the end of the story, there are some symbols which symbolize Jonas' success. Thus, it proves Bourdieu's statement that, resistance is possible, that at one point, symbolic violence is able to create an impact on physical resistance.

\section{CONCLUSIONS}

Based on the findings and the discussion of the kinds of values, and the ways those values are represented in The Giver, the researcher draws conclusions, as represented in the following.

The Giver delivers five kinds of symbolic violence; they are symbolic violence to repress choices, to eliminate individuality, to manipulate history, to hide feelings, and to finish one's life. The symbolic violence is delivered through two prominent literary elements; they are character and point of view. Although, the story uses both characters' actions and conversation, to reveal the symbolic violence, the characters' speech are most frequently occurring, to deliver those 
symbolic violence, rather than through the action. In addition, symbolic violence is delivered through the collective characters, rather than by one character. The characters who deliver symbolic violence are The Committee, Chief of Elder, and Jonas' parents. The root of doing symbolic violence is domination. The Committee wants to perform their power to the community, by designing some rules to the citizens of the community.

Although, in one side the parents are the member of the community, who also get symbolic violence in the house, they also become the actors who do symbolic violence to their children, especially Jonas. So, the social parents become the dominated people, in the domestic field, they become the dominant people. Thus, in this case, Jonas as a child experience double domination; in community and in the domestic field.

Related to the impact of the symbolic violence, reflected in the story, basically, the majority people accept the violence. It is proved through their obedience, to the rules as the best way of life, without asking why they have to obey the rules. On the other hand, the symbolic violence also creates resistance, as reflected in the character of Jonas, when he breaks the rules of the community.

Because, literature is a reflection of life, so what is reflected in The Giver can be seen as the "mirror" of life. Indeed, symbolic violence can exist in everywhere, and can be done or experienced by everyone. It is because, human's desire to get power always appears. However, the most important thing that must be remembered by the dominant people is, about the impact of symbolic violence itself, because, actually it can emerge resistance, that is worse than the symbolic violence itself. On the other hand, the dominated people also should realize that, symbolic violence is actually constructed. So, they can fight it and not just accept it, to change the domination itself, as portrayed by the character of Jonas.

\section{REFERENCES}

1. Bourdieu, Pierre and T. Eagleton. 1992. “In Conversation: Doxa and Common Life”. New Life Review 191, 111-112.

2. Bourdieu, Pierre. 1991. Language and Symbolic Power. Cambridge: Polity.

3. Bourdieu, Pierre and Jean-Claude Passeron. 1990. Reproduction in Education, Society, and Culture. London: Sage Publications.

4. Bourdieu, Pierre. 19989. Social Space and Symbolic Power. Sociological Theory 7, 14-25.

5. Grenfell, Michael. 2008. Pierre Bourdieu Key Concept. Stocksfield: Acumen Publishing Limited.

6. Haryatmoko. 2016. MembongkarRezimKepastian. Yogyakarta: Kanisius.

7. Lowry, Lois. 1993. The Giver. New York: Dell Laurel-Leaf.

8. Lukens, Rebecca J. 1999. A Critical Handbook of Children's Literature (Sixth Edition). New York: Longman.

9. Moleong, L. 2010. MetodologiPenelitianKualitatif(Revised Ed.). Bandung: PT. RemajaRosdakarya.

10. Vanderstoep Scott W., and Johnston, Deidre D. 2009.Research Methods for Everyday Life. United Kingdom: Jossey Bass Wiley. 
